\title{
5. Strategic commitments and the principle of reciprocity in interconnection pricing
}

\author{
Nicholas Economides, Giuseppe Lopomo and \\ Glenn Woroch
}

\section{INTRODUCTION}

Interconnection of telecommunications networks was mandated by the Telecommunications Act of 1934 and has been a continuing feature of the regulatory environment in the United States and in public switched telecommunications networks all over the world. Interconnection was mandated because of the glaring divergence between private and public interests as telecommunications evolved in the last two decades of the 19th century and the first two decades of the 20th century. During this period, after the expiration of the original Bell patents, AT\&T developed a monopoly long-distance network while a plethora of local telecommunications companies (independents) emerged so that in the early 1920s more local lines belonged to the independents than to AT\&T. ${ }^{1}$ AT\&T leveraged its monopoly bottleneck in long-distance and refused to interconnect independent local telecommunications companies to its long-distance network unless they became part of the Bell System, which essentially meant unless they were acquired. The wisdom of the regulatory rule of mandatory interconnection lies in that it helps eliminate foreclosure arising from a bottleneck of a part of the network. Mandatory interconnection helps society to reap the full benefits of network effects of the interconnected network rather than the much smaller network effects ${ }^{2}$ of its constituent disconnected parts. ${ }^{3}$

The possibility of foreclosure of competitors is obvious in a one-sided bottleneck such as the one that AT\&T possessed at the end of the 19th century. However, the possibility of foreclosure also arises in a more subtle 
way in a world of two-sided bottlenecks where each telephone company possesses a bottleneck but also requires the use of the opponents' bottleneck to provide end-to-end services. Suppose, for example, that two companies (local exchange carriers) provide local telecommunications services in New York City and each consumer subscribes to only one telephone company. Each local exchange carrier (LEC) possesses a bottleneck that is required by the competing company to complete calls across networks, when the originating party and the terminating party subscribe to different LECs. The dependence of each company on the others' network, at a first glance, may seem to provide equal negotiating power to each network, and therefore eliminate the possibility of foreclosure at an unregulated market equilibrium. This conjecture is incorrect. In this chapter, it is shown that, in the absence of regulation, a local telecommunications company with significant market share can set interconnection fees so that a local rival is foreclosed at the unregulated market equilibrium. Briefly, foreclosure of rivals is achieved by the imposition by a dominant firm of high termination fees, which are the fees that rivals have to pay to the dominant firm to have calls terminate in the dominant firms' network. Imposition of such high fees increases the cost (and price) of calls originating from a rival network and terminating in the dominant network. Since such calls represent the lion's share of the rival's calls, their high prices put the rival at a competitive disadvantage compared to the dominant firm. Thus, consumers prefer to subscribe to the dominant network and rivals are foreclosed.

This is not just a theoretical result. In the deregulated environment of New Zealand where interconnection fees are privately negotiated and hotly contested, Telecom New Zealand (the incumbent dominant carrier) has set interconnection fees so that entrants were foreclosed. ${ }^{4}$ As the United States, the European Union and most of the rest of the world are progressively deregulating telecommunications markets, it is obviously important to avoid full deregulation where it leads to publicly undesirable outcomes, such as foreclosure. Since the general effects of deregulation in stimulating competition and improving efficiency are desirable, it would be useful to have a particular regulatory rule which, in the presence of an otherwise deregulated environment, would eliminate anti-competitive behaviour. In this chapter, such a regulatory rule is presented: reciprocity of termination fees. This rule imposes the restriction that the termination fee set by Network 1 is equal to the termination fee set by the Network 2, provided that costs to terminate calls are equal in the two networks. It is shown that this rule eliminates foreclosure equilibria. When the two networks have different costs, the appropriate regulatory rule is shown to impose the requirement that termination price to cost margins are equal in the two networks (symmetric reciprocity in mark-ups). These results underscore the wisdom of the Telecommunications Act of 1996 that mandates that interconnection fees be based on reciprocal terms. ${ }^{5}$ The issue of termination pricing also arises in 
mobile networks where in early years termination fees were high. Given the fact that in many cases costs differ across mobile networks (for example, because they have increasing returns to scale and different market shares) regulators should be careful to use 'symmetric reciprocity in mark-ups' setting equal termination price to cost margins, since setting termination fees equal to the lowest cost among the providers could lead to foreclosure of rivals.

Competition is modelled in a modified Hotelling Main Street framework, with two horizontally differentiated networks and a continuum of consumers with ideal points uniformly distributed on a segment joining the two networks locations. The following extensive-form game is studied. First, the consumers choose which network they want to subscribe to. In a second stage, the networks set their prices, and finally the consumers choose their telephone consumption levels. In making their subscription decision, consumers correctly anticipate the prices that the two networks are going to set in equilibrium in the second stage. This game structure is chosen for the following reasons. First, the model intends to capture situations where consumers are slower in changing network affiliation than in varying the amount of phone calls they make as firms change prices: one can think of the second stage of the game as the 'short run', and of the first stage as the 'long run'. Telecommunications providers have observed that consumers are slow to change network affiliation. ${ }^{6}$ Second, the more traditional game in which consumers make their subscription decision after the networks have chosen their prices does not have equilibria in pure strategies for a wide range of parameters values and model specifications when interconnection fees are chosen strategically. ${ }^{7}$

The main results are as follows. When the networks have equal costs and equal numbers of subscribers and set their prices simultaneously, they charge equal interconnection fees to each other. Thus, symmetric reciprocity in interconnection pricing is a feature of the market equilibrium when networks are of equal size. Also modelled is a setup when one of the networks sets prices first. A dominant (incumbent) network facing an entrant has a natural first-mover's advantage in the termination fee, since the entrant has to accept an interconnection agreement to start business. That this advantage allows the first-movers to charge higher prices for incoming calls to his network is shown.

The strategic advantage of the first-mover is eliminated if firms are restricted to charge each other the same termination access fee, that is, if symmetric reciprocity is imposed. When symmetric reciprocity is not imposed, even under strategic symmetry and simultaneous moves, pricing exhibits 'double marginalisation', that is, calls across networks are overpriced because each network fails to take into account the effects of its price changes on the opponent's profit. ${ }^{8}$ However, the imposition of symmetric reciprocity fully internalises the vertical externality, thus eliminating the 
double marginalisation and resulting in termination prices at cost, as well as in lower end-to-end prices. Thus, the application of the rule of symmetric reciprocity can improve social welfare.

In the long run, each consumer subscribes to (at most) one network. When symmetric reciprocity is not imposed, multiple subscription equilibria may exist, including corner equilibria where one of the networks has zero size and the other network is a monopoly. A first-mover advantage in setting termination fees typically results in a larger size for the first-moving network, although corner equilibria may arise once again. However, the imposition of symmetric reciprocity in termination pricing eliminates the possibility of corner equilibria. Thus, the imposition of the conduct rule of symmetric reciprocity has significant structural effects. The eliminated corner equilibria have higher 'transportation costs', (that is, subscribers' disutility) hence lower consumer surplus. Therefore, the structural and behavioural effects of imposing a symmetric reciprocity rule on interconnection fees are highly beneficial.

An early version of this chapter circulated before most of the literature on two-sided bottlenecks in telecommunications. Laffont et al. (1998) analyse a similar structure. They limit the analysis to the case in which the interconnection fees are set exogenously and equal to each other, at a relatively low level. Hence, their analysis cannot capture the strategic implications of a network's ability to control the termination fee that a rival network would have to pay; one of the main goals in this paper. Instead, Laffont et al. focus on the possibility that the two networks may collude in achieving higher output prices through collusion in access fees that are essentially inputs that each network supplies to the other.

The rest of the chapter is organised as follows. The next section sets up the network structure, derives the demand and profit functions, and discusses the various game structures considered. Following that the subsequent section characterises all equilibria of the various game structures and compares them. The final sections present welfare results and contain extensions and generalisations.

\section{THE MODEL}

\section{Network Structures}

Suppose that two firms (networks), $i=1,2$, offer local access for telephone services in the same area to the same continuum of consumers. Assume that each consumer can subscribe to at most one network. The two networks are interconnected, so that a customer of Network $i$ can call any customer of Network $j$, as well as any customer of Network $i$. 


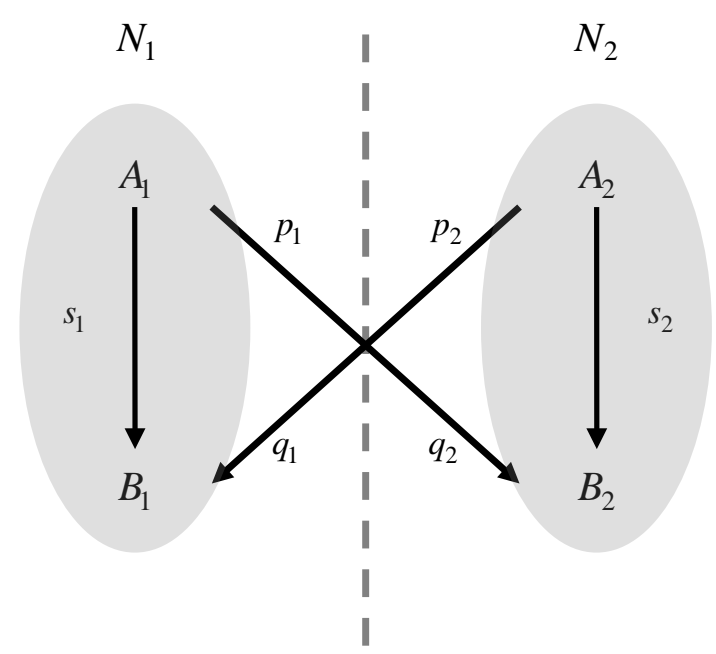

Figure $5.1 \quad$ Network structure

Each phone call can be thought of as consisting of an originating part $A_{i}$ and a terminating part $B_{j}$, where $i$ and $j$ refer to the identities of the networks of origination and termination. Each Network $i$ sets three prices: a price $s_{i}$ for 'internal' calls, that is, calls that originate and terminate in the network; an origination fee $p_{i}$ for 'outgoing' calls, that is, calls that originate in Network $i$ and terminate in the other network; and a termination fee $q_{i}$ for 'incoming' calls, that is, calls that originate in the other network and terminate in Network $i$.

\section{Table $5.1 \quad$ Call types and prices}

\begin{tabular}{lccc}
\hline \multicolumn{1}{c}{ Call type } & $\begin{array}{c}\text { Price charged by } \\
N_{1}\end{array}$ & $N_{2}$ & \\
\hline Within $N_{1}: A_{1}$ to $B_{1}$ & $s_{1}$ & 0 & $s_{1}$ \\
From $N_{1}$ to $N_{2}: A_{1}$ to $B_{2}$ & $p_{1}$ & $q_{2}$ & $p_{1}+q_{2}$ \\
Within $N_{2}: A_{2}$ to $B_{2}$ & 0 & $s_{2}$ & $s_{2}$ \\
From $N_{2}$ to $N_{1}: A_{2}$ to $B_{1}$ & $q_{1}$ & $p_{2}$ & $p_{2}+q_{1}$ \\
\hline
\end{tabular}

The four possible types of calls, with the corresponding prices are as shown above in Table 5.1. 


\section{Demand and Profit Functions}

Consumers perceive the two networks as horizontally (variety) differentiated; they are distributed uniformly according to their ideal network on the interval $[0,1]$. The consumer who has the highest preference for Network 1 (respectively 2) is 'located' at point 0 (respectively 1 ). ${ }^{10}$ Thus, a consumer of type $z \in[0,1]$ who subscribes to network $i$ derives total utility $V_{z}(i)$, where:

$$
\begin{gathered}
V_{z}(1)=U_{1}-\lambda z, \\
V_{z}(2)=U_{2}-\lambda(1-z)
\end{gathered}
$$

and $U_{i}$ is her consumer surplus from buying telephone services from network $i$. The parameter $\lambda \in(0, \infty)$ measures the strength of preference for variety, that is, the degree of perceived horizontal differentiation.

A consumer potentially makes calls to all other consumers. Denote by $x(\theta)$ the quantity of phone calls that she makes to consumer $\theta$, where $\theta \in[0,1]$. Assume that all consumers have the same preferences over telephone calls (calling profiles/patterns) $\{x(\theta) ; \theta \in[0,1]\}$ and the outside good ('money') $m$.

Two cases are analysed. First, consider general separable preferences represented by the functional: ${ }^{11}$

$$
U_{s}(x, m)=\int_{0}^{1} u\left(x_{\theta}\right) d \theta+m
$$

where $u:[0, \infty) \rightarrow[0, \infty)$, with

$$
u(0)=0, u^{\prime}>0, u^{\prime \prime}>0
$$

and

$$
2 u^{\prime \prime}(y)+y u^{\prime \prime}(i) \leq 0^{12} .
$$

Second, to capture substitutability between calls to any two different subscribers, consider the case of quadratic preferences: ${ }^{13}$

$$
U(x, m)=\int_{0}^{1}\left(a x_{\tau}-\frac{b}{2} x_{\tau}^{2}\right) d \tau-\frac{c}{2} \int_{0}^{1} \int_{0}^{1} x_{\tau} x_{\theta} d \tau d \theta+m
$$


for $0 \leq x_{\theta} \leq a / b$, where $a, b$ and $c$ are positive real numbers, such that $c \in[0, b)$. The degree of substitutability between calls to any two different subscribers increases with $c$. At $c=0$ all phone calls are independent goods, and this becomes a special representation of the general separable case. ${ }^{14}$

Let consumers in subset $N_{i} \subset[0,1]$ of measure $n_{i}$ subscribe to network $i=1,2$. The budget constraint of subscriber $\theta$ of Network 1 is:

$$
s_{1} \int_{N_{1}} x(\tau) d \tau+\left(p_{1}+q_{2}\right) \int_{N_{2}} x(\tau) d \tau+m=M_{\theta},
$$

where $M_{\theta}$ is her total wealth.

With separable preferences, maximising $U$ subject to the budget constraint yields the same demand function $x$, equal to the inverse of $u^{\prime}$, for both types of calls, independent of the network sizes $n_{i}$ and $n_{j}$. Denoting $v(s) \equiv \max _{x}\{u(x)-s x\}$, the consumer's surplus function is:

$$
U_{s}\left(s_{i}, p_{i}+q_{j}, n_{i}, n_{j}\right)=n_{i} v\left(s_{i}\right)+n_{j} v\left(p_{i}+q_{j}\right) .
$$

For the quadratic case, maximising $U$ subject to the budget constraint yields both her demand function for internal calls $x_{i i}$ (that is, to any other customer of the same network) and her demand function for outgoing calls $x_{i j}$ (that is, to each customer of the other network):

$$
\begin{gathered}
x_{i i}\left(s_{i}, p_{i}+q_{j} ; n_{i}, n_{j}\right)=\frac{1}{\gamma}\left(a-s_{i}+\frac{c}{b} n_{j}\left(p_{i}+q_{j}-s_{i}\right)\right), \\
x_{i j}\left(p_{i}+q_{j}, s_{i} ; n_{i}, n_{j}\right)=\frac{1}{\gamma}\left(a-p_{i}-q_{j}+\frac{c}{b} n_{i}\left(s_{i}-p_{i}-q_{j}\right)\right),
\end{gathered}
$$

where $\gamma \equiv b+c\left(n_{1}+n_{2}\right)$. Substituting these demands into the utility function yields the consumer surplus for each subscriber of Network $i$ :

$$
U\left(s_{i}, p_{i}+q_{j}, n_{i}, n_{j}\right)=n_{i} \frac{\left(a-s_{i}\right)^{2}}{2 \gamma}+n_{j} \frac{\left(a-p_{i}-q_{j}\right)^{2}}{2 \gamma}+c n_{i} n_{j} \frac{\left(p_{i}+q_{j}-s_{i}\right)^{2}}{2 b \gamma} .
$$

Therefore, for both specifications of preferences, the model exhibits network externalities: given prices $s_{i} \in[0, a)$ and $p_{i}$ and $q_{j}$ such that $p_{i}+q_{j} \in[0, a)$, 
the welfare of each consumer is increasing in both $n_{i}$ and $n_{j}$, that is, the consumer derives positive externalities from expansion of each of the two networks. If the calls are independent goods, $U$ and $U_{s}$ are linear in $n_{i}$ and $n_{j}$ : each new subscriber increases the consumer's surplus by the same amount. Under non-separable preferences, $U$ is strictly concave, since the addition of a new subscriber reduces the value of calling the other subscribers.

In the main part of the chapter, it is assumed that the fixed costs are zero and normalise the marginal cost to zero. This assumption is relaxed in the 'Extensions' section where the two networks are allowed to have different marginal costs. ${ }^{15}$ Under non-separable preferences, Firm $i$ 's profit function is: ${ }^{16}$

$$
\begin{aligned}
\Pi_{i}\left(s_{i}, p_{i}, q_{j}, n_{i}, n_{j}\right) & =s_{i} n_{i}^{2} x_{i i}\left(s_{i}, p_{i}+q_{j} ; n_{i}, n_{j}\right) \\
& +p_{i} n_{i} n_{j} x_{i j}\left(p_{i}+q_{j}, s_{i} ; n_{i}, n_{j}\right) \\
& +q_{i} n_{i} n_{j} x_{j i}\left(p_{j}+q_{i}, s_{j} ; n_{i}, n_{j}\right)
\end{aligned}
$$

and, with separable preferences, the Firm $i$ 's profit is:

$$
\begin{aligned}
\Pi_{i}\left(s_{i}, p_{i}, q_{j}, n_{i}, n_{j}\right) & =s_{i} n_{i}^{2} x\left(s_{i}\right)+p_{i} n_{i} n_{j} x\left(p_{i}+q_{j}\right) \\
& +q_{i} n_{i} n_{j} x\left(p_{j}+q_{i}\right) .
\end{aligned}
$$

In both cases, the three terms represent, respectively, the revenue from internal, outgoing, and incoming calls.

\section{Game Structures}

The interaction among the networks and the consumers is modelled as a twostage game. In the first stage, all consumers simultaneously make their subscription decisions. In the second stage, the networks set their prices, and the consumers choose their consumption levels. Thus, the consumers cannot change their subscription decision after observing the networks' prices. This does not mean that, when making the subscription decision, the consumers are uncertain about the prices set by the networks in the second stage: in equilibrium, they anticipate correctly all other parties' actions.

Three alternative structures are analysed for the second stage. First, in the benchmark structure, there is strategic symmetry, that is, the firms set all six prices simultaneously. Second, a game is analysed where one firm (Firm 1) sets its interconnection fee $q_{1}$ in advance. This structure captures situations where a dominant network is able to set its interconnection charge before the 
other network has a chance to play. This happens, for example, when there is a single incumbent, and an entrant needs an interconnection agreement (specifying the termination fee) before starting business. Finally, in the third game, Firm 1 chooses the interconnection fee under the constraint of symmetric reciprocity in termination fees, that is, $q_{1}=q_{2}$.

Both the case where the interconnection fee is set before the other prices, and the case where all six prices are set simultaneously are analysed. Symmetric reciprocity is imposed by law in many but not all jurisdictions. For example, in the United States reciprocal compensation of call termination is mandated by the Telecommunications Act of 1996, section 251(b)(5). On the other hand, the law is silent on symmetric reciprocity in New Zealand, and the issue of reciprocal termination pricing is central in the negotiations between telecommunications service providers.

\section{ANALYSIS}

\section{Game 1: Strategic Symmetry}

\section{Equilibrium prices}

To find the sub-game perfect equilibria, start by solving by backward induction. In the second stage, the networks set their prices simultaneously, given their sizes $n_{1}$ and $n_{2}$. The next proposition characterises the equilibrium prices.

Proposition 1: With general separable preferences, for $n_{1}>0, n_{2}>0$, the equilibrium prices are:

$$
s_{i}^{(1)}=s^{m}, p_{i}^{(1)}=q_{i}^{(1)}=t^{o} / 2,
$$

with $i=1,2$, where

$$
x\left(s^{m}\right)+s^{m} x^{\prime}\left(s^{m}\right) \equiv 0
$$

and

$$
x\left(t^{o}\right)+\frac{t^{o}}{2} x^{\prime}\left(t^{o}\right) \equiv 0
$$


Moreover, $s^{m}<t^{o}$. If $n_{j}=0$, then $s_{i}^{(1)}+s^{m}$ and all other prices can take arbitrary values. For proof see Appendix.

With non-separable quadratic preferences, for $n_{1}>0, n_{2}>0$, the equilibrium prices are:

$$
\begin{gathered}
s_{i}^{(1)}=a / 2, \\
p_{i}^{(1)}\left(n_{i}\right)=\frac{a\left(2 b+3 c n_{i}\right)}{6\left(b+c n_{i}\right)}, \\
q_{j}^{(1)}\left(n_{i}\right)=\frac{a b}{3\left(b+c n_{i}\right)},
\end{gathered}
$$

with $i=1,2$. If $n_{j}=0$, then $s_{i}^{(1)}=a / 2$ and all other prices can take arbitrary values.

A number of observations are in order. First, under both preference specifications, and for any network size $n_{i} \in(0,1), s_{i}^{(1)}<p_{i}^{(1)}+q_{j}^{(1)}$; that is, outgoing calls are sold at a higher price than internal calls. ${ }^{17}$ This result is due to the fact that, while each Network $i$ supplies both components of its internal calls (the originating part $A_{i}$ and the terminating part $B_{i}$ ), the two components of any outgoing call are sold by different networks. In the price setting process for outgoing calls, each firm fails to internalise the full benefit of a reduction in the price of its components. Thus, the perceived elasticity of demand is lower, and hence the equilibrium total price $p_{i}+q_{j}$ is higher, than the joint monopoly profit-maximising price. ${ }^{18}$

Second, in general, parity fails to occur. Parity for interconnection holds when a network has to charge its customers the same amount it charges others for interconnection. Here parity fails since the larger network charges more for its origination and termination services when they are sold as part of hybrid calls than when they are used by itself, that is, if $n_{i}>n_{j}$, then $s_{i}<p_{i}+q_{i}$.

Moreover, under non-separable preferences, the following additional results arise. First, the origination fee of an outgoing phone call is always larger than the termination fee of the same call, $p_{i}^{(1)}>q_{j}^{(1)}$. This is because the originating network has a strategic incentive to keep the price of outgoing calls high, since they are substitutes with its internal calls. On the other hand, the terminating network has no strategic incentive to keep termination prices 
high, since the incoming call is not a substitute for its internal calls or for outgoing calls that originate from it.

Second, the equilibrium origination fee $p_{i}^{(1)}$ and termination fee $q_{j}^{(1)}$ for outgoing calls are, respectively, increasing and decreasing functions of the originating (i) network's size, $d p_{i}^{(1)} / d n_{i}>0, d q_{j}^{(1)} / d n_{i}<0$, while the price of outgoing calls decreases in the size of the originating network, $d\left(p_{i}^{(1)}+q_{j}^{(1)}\right) / d n_{i}<0$. These are all consequences of the relative strategic strengths of the two networks. As the size of Network $i$ increases, its stronger strategic power is reflected in a higher origination fee; this prompts a sharply lower termination fee by the opponent network, so that a hybrid call has a lower price despite the increase in its origination fee.

Third, as a consequence of the inequalities stated above, if Network $i$ is larger than Network $j, n_{i}>n_{j}$, its outgoing calls are offered at a lower price, $p_{i}+q_{j}<p_{j}+q_{i}$, but its origination and termination fees are higher, $p_{i}>p_{j}, q_{i}>q_{j}$. Therefore, if network sizes differ, $n_{i} \neq n_{j}$, symmetric reciprocity fails.

\section{The subscription decision}

Now turn to the analysis of the consumers' subscription decisions. In equilibrium, each consumer makes her choice, correctly anticipating the simultaneous choices of all other consumers as well as the prices that the firms will set in the second stage, as given in Proposition 1. When the consumers in subset $N_{i}$ of measure $n_{i}$ subscribe to network $i, i=1,2$, the overall realised indirect utility of the consumer located at point $\theta$, is $V^{(1)}\left(n_{1}, n_{2}\right)-\lambda \theta$, if she subscribes to Network 1 , and $V^{(1)}\left(n_{2}, n_{1}\right)-\lambda(1-\theta)$ if she subscribes to Network 2, where: ${ }^{19}$

$$
V^{(1)}\left(n_{i}, n_{j}\right) \equiv U\left(s_{i}^{(1)}, p_{i}^{(1)}\left(n_{i}\right)+q_{j}^{(1)}\left(n_{i}\right), n_{i}, n_{j}\right)
$$

and similarly for the separable case. Thus, in the non-separable case,

$$
V^{(1)}\left(n_{i}, n_{j}\right)=\frac{a^{2}\left(4 b n_{j}+9 b n_{i}+9 c n_{i} n_{j}+9 c n_{i}^{2}\right)}{72 \gamma\left(b+c n_{i}\right)}
$$

and, in the separable case:

$$
V_{s}^{(1)}\left(n_{i}, n_{j}\right)=n_{i} v\left(s^{m}\right)+n_{j} v\left(t^{o}\right) .
$$


For both preference specifications, the consumer welfare increases in the size of each network, that is, all derivatives:

$$
\begin{aligned}
& \frac{\partial}{\partial n_{i}} V^{(1)}\left(n_{i}, n_{j}\right), \\
& \frac{\partial}{\partial n_{j}} V^{(1)}\left(n_{i}, n_{j}\right) \text { and } \frac{\partial}{\partial n_{i}} V_{s}^{(1)}\left(n_{i}, n_{j}\right), \\
& \hline n_{j}
\end{aligned}
$$

are positive. Thus, the market mediated indirect utility function exhibits network externalities.

The next proposition characterises all equilibria of Game 1. An equilibrium is indicated as a pair $\left\{n_{1}, n_{2}\right\}$ of network sizes.

Proposition 2: For all parameter values and both consumer preference specifications, $\{0,0\}$ is an equilibrium. In addition, with non-separable quadratic preferences, the equilibrium correspondence is determined by five numbers $\lambda_{1}^{(1)}<\ldots<\lambda_{5}^{(1)}$ (defined in the Appendix) as follows:

- $\quad\{\{1 / 2,1 / 2\},\{0,1\},\{1,0\}\}$, for $0<\lambda \leq \lambda_{1}^{(1)}$;

- $\{\{1 / 21 / 2\},\{0,1\},\{1,0\},\{1 / 2-\delta(\lambda), 1 / 2+\delta(\lambda)\},\{1 / 2+\delta(\lambda), 1 / 2-\delta(\lambda)\}\}$,

where

$$
\delta(\lambda) \equiv \sqrt{\frac{b}{c^{2}}\left(\frac{(c+2 b)^{2}}{4 b}-\frac{5 a^{2}}{72 \lambda}\right)}, \text { for } \lambda_{1}^{(1)}<\lambda<\lambda_{2}^{(1)} ;
$$

- $\{\{1 / 2,1 / 2\},\{0,1\},\{1,0\}\}$, for $\lambda_{2}^{(1)} \leq \lambda \leq \lambda_{3}^{(1)}$;

- $\quad\{\{1 / 2,1 / 2\}\}$, for $\lambda_{3}^{(1)} \leq \lambda \leq \lambda_{4}^{(1)}$;

- $\quad\left\{\left\{n_{*}^{(1)}(\lambda), n_{*}^{(1)}(\lambda)\right\}\right\}$

where 


$$
\begin{aligned}
& n_{*}^{(1)}(\lambda) \equiv \frac{1}{48 c \lambda}\left(3 a^{2}-36 \lambda b+\sqrt{\left(9 a^{4}-8 a^{2} \lambda b+144 \lambda^{2} b^{2}\right)}\right), \\
& \text { for } \lambda_{4}^{(1)}<\lambda<\lambda_{5}^{(1)} .
\end{aligned}
$$

With separable preferences, the equilibrium correspondence consists of:

- $\quad\{\{1 / 2,1 / 2\},\{0,1\},\{1,0\}\}$, for $0<\lambda<v\left(s^{m}\right)-v\left(t^{o}\right)$;

- $\{\{n, 1-n\} ; 0 \leq n \leq 1\}$, for $\lambda=v\left(s^{m}\right)-v\left(t^{o}\right)$;

- $\quad\{\{1 / 2,1 / 2\},\{0,1\},\{1,0\}\}$, for $v\left(s^{m}\right)-v\left(t^{o}\right)<\lambda<v\left(s^{m}\right)$;

- $\quad\{\{1 / 2,1 / 2\}\}$, for $v\left(s^{m}\right)<\lambda<v\left(s^{m}\right)+v\left(t^{o}\right)$; and

- $\{\{n, n\} ; 0 \leq n \leq 1 / 2\}$, for $\lambda=v\left(s^{m}\right)+v\left(t^{o}\right)$.

For proof see Appendix.

Proposition 2 establishes that, except when $\lambda$ is large $\left(\lambda>\lambda_{5}^{(1)}\right)$, Game 1 has multiple equilibria. However, imposing the requirement that the equilibria satisfy a notion of stability (see below) restricts the equilibrium set as follows: in the separable case, only one equilibrium is stable for almost all parameter values; under non-separable preferences, there is a unique stable equilibrium except for $\lambda \in\left[\lambda_{1}^{(1)}, \lambda_{2}^{(1)}\right]$, where both the corner equilibria and the symmetric equilibrium are stable.

To define the stability notion, suppose that each consumer assigns a positive probability to the event that a (small, but of positive) fraction of consumers do not make their equilibrium subscription decision and that, if the corner outcome $n_{i}=1-n_{j}=1$ occurs, the firm will set prices $p_{i}(1)=\frac{a(2 b+c)}{6 b+c)}, q_{j}(1)=\frac{a b}{3(b+c)}$, and $p_{j}=0=q_{i}(0)=a / 3$. That is, the equilibrium is 'unstable' if, in this case, some consumers have an incentive to revise their choice. This notion of stability is in the same spirit as Selten's notion of trembling hand perfection in finite games. Selten's notion cannot be applied directly, since it was defined only for finite games.

According to this notion, $\{0,0\}$ is unstable whenever another equilibrium exists. Also, under separable preferences, $\left\{1 \frac{12,1 / 2\}}{2}\right.$ is unstable for 
$\lambda<v\left(s^{m}\right)-v\left(t^{o}\right)$; and the corner equilibria are unstable for $v\left(s^{m}\right)-v\left(t^{o}\right)<\lambda<v\left(s^{m}\right)$. Thus, neglecting the knife edge cases where $\lambda \in\left\{v\left(s^{m}\right)-v\left(t^{o}\right), v\left(s^{m}\right)+v\left(t^{o}\right)\right\}$, the only 'stable' equilibria are the corner ones for $\lambda<v\left(s^{m}\right)-v\left(t^{o}\right)$ and the symmetric one for $v\left(s^{m}\right)-v\left(t^{o}\right)<\lambda$.

Under non-separable preferences, the stability notion eliminates the symmetric equilibrium for $\lambda<\lambda_{1}^{(1)}$, the two interior asymmetric equilibria whenever they exist (that is, for $\lambda_{1}^{(1)}<\lambda<\lambda_{2}^{(1)}$ ), and the corner equilibria for $\lambda_{2}^{(1)}<\lambda<\lambda_{3}^{(1)}$.

To interpret the structure of the equilibrium correspondence, note the forces that determine them. First, consumers want to belong to a large network because prices of internal calls are lower than prices of calls across networks. Second, the benefit to a consumer of joining a network is diminished by the loss of utility which this consumer incurs because the prospective network does not coincide with her 'most preferred' network specification. This 'horizontal differentiation' cost is measured by $\lambda$. Each network's size is determined by its marginal consumer who, in equilibrium, must weakly prefer joining her chosen network to both joining the other network and not joining any network. Thus, different values of $\lambda$ imply different equilibria. If the preferences for variety are not strong, that is, $\lambda \in\left(0, \lambda_{1}^{(1)}\right)$, the incentive to congregate at a single network dominates. Hence, the corner equilibria exist and the symmetric equilibrium is unstable. As $\lambda$ increases and enters the interval $\left(\lambda_{1}^{(1)}, \lambda_{2}^{(1)}\right)$, the symmetric equilibrium becomes stable. In the interval $\left(\lambda_{2}^{(1)}, \lambda_{4}^{(1)}\right)$ there are no stable corner equilibria, and the unique stable equilibrium is the symmetric one. For $\lambda \in\left(\lambda_{4}^{(1)}, \lambda_{5}^{(1)}\right)$, there is a unique, symmetric equilibrium with partial coverage. Full coverage equilibria disappear since, for the consumer located at $1 / 2$, the horizontal differentiation cost now outweighs the net benefit from joining any network. As $\lambda$ increases further, the size of each network shrinks to zero. Finally, for $\lambda \geq \lambda_{5}^{(1)},\{0,0\}$ remains the only equilibrium.

\section{Game 2: Commitment by One Network on the Termination Fee}

\section{Equilibrium prices}

In this game, given the network sizes from Stage 1, pricing takes place sequentially. First, Firm 1 sets its termination fee $q_{1}$. Then both firms set all other prices simultaneously. For simplicity, the analysis is restricted to the 
case of quadratic preferences, including the (separable) case where $c=0$. In the short run, Firm 1 chooses the interconnection fee before its opponent.

Proposition 3: In Game 2, with quadratic preferences, the equilibrium prices $s_{1}^{(2)}, s_{2}^{(2)}, p_{1}^{(2)}$ and $q_{2}^{(2)}$ are equal to the corresponding ones in Game 1. Moreover,

$$
p_{2}^{(2)}=a \frac{b+2 c n_{2}}{4\left(b+2 c n_{2}\right)}<p_{2}^{(1)}
$$

and

$$
q_{1}^{(2)}=\frac{a b}{2\left(b+c n_{2}\right)}>q_{1}^{(1)} .
$$

Further,

$$
p_{2}^{(2)}+q_{1}^{(2)}>p_{2}^{(1)}+q_{1}^{(1)}
$$

and

$$
p_{1}^{(2)}>p_{2}^{(2)}, q_{1}^{(2)}>q_{2}^{(2)}
$$

A number of observations are in order. First, the strategic advantage of being able to commit on the interconnection fee allows Firm 1 to charge higher origination and termination fees than its rival, $p_{1}^{(2)}>p_{2}^{(2)}, q_{1}^{(2)}>q_{2}^{(2)}$, for any network sizes in the separable case as well as when the two networks are of equal sizes in the non-separable case. Thus, symmetric reciprocity fails. Under the same conditions, outgoing calls from Network 1 are cheaper than outgoing calls from Network 2, $p_{2}^{(2)}+q_{1}^{(2)}>p_{1}^{(2)}+q_{2}^{(2)}$. These conclusions derive from the strategic advantage of the leader.

Parity also fails in general. The leader always prices its origination and termination components higher to others than to itself, that is, $s_{1}^{(2)}<p_{1}^{(2)}+q_{1}^{(2)}$. On the other hand, the follower may price its components lower to others than to itself.

A number of the qualitative results of the simultaneous game are preserved. First, internal calls are cheaper than outgoing calls. Second, origination fees are increasing in the size of the originating network, and, third, termination fees and total fees for outgoing calls are decreasing in the size of the originating network. Fourth, the customers of Network 1 face the 
same prices as in Game 1: hence their welfare remains unchanged. Fifth, the customers of Network 2 face a higher price for their outgoing calls (but the same price for the internal calls), and so their surplus is lower than in Game 1. It follows that total consumer surplus is lower in Game 2.

\section{The subscription decision}

In the first stage, the consumers make their subscription decisions. The next proposition characterises all equilibria $\left\{n_{1}, n_{2}\right\}$ for the separable utility case.

Proposition 4: The equilibrium correspondence is as follows:

- $\left\{\{1,0\},\left\{n_{*}^{(2)}(\lambda), 1-n_{*}^{(1)}(\lambda)\right\},\{0,1\}\right\}$,

where

$$
n_{*}^{(2)}(\lambda) \equiv 4 \frac{5 a^{2}-72 \lambda b}{47 a^{2}-576 \lambda b},
$$

$$
\text { for } 0<\lambda \leq \frac{5 a^{2}}{72 b}
$$

- $\{\{1,0\}\}, \frac{5 a^{2}}{72 b}<\lambda<\frac{3 a^{2}}{32 b}$,

- $\left\{\left\{n_{*}^{(2)}(\lambda), 1-n_{*}^{(2)}(\lambda)\right\}\right\}$ for $\frac{3 a^{2}}{32 b}<\lambda<\frac{a^{2}}{6 b}$.

For proof see Appendix.

Notice that symmetric equilibria, $n_{1}=n_{2}=1 / 2$, never exist. Unique asymmetric interior equilibria with full coverage exist in two separate regions of $\lambda$. When $\lambda$ is large, the full coverage equilibrium is stable and Network 1 is larger, benefiting from its first-mover advantage. When $\lambda$ is small, the full coverage equilibrium is unstable and Network 2 is larger. It is not likely that such equilibria will be observed. 


\section{Game 3: Commitment in the Termination Fee with Symmetric Reciprocity}

Next consider the case when Network 1 chooses the interconnection fee subject to symmetric reciprocity: $q_{1}=q_{2}=q$. Thus, Firm 1 is unable to create a difference in interconnection fees to its advantage, although it has control over its rival's termination fee. Two game structures are analysed. In the first (Game 3.1), Network 1 sets $q_{1}=q_{2}=q, s_{1}$, and $p_{1}$ and, simultaneously, Firm 2 chooses $s_{2}$ and $p_{2}$. The second game structure (Game 3.2) has one additional stage. Network 1 chooses $q$ in advance; subsequently Network 1 chooses $s_{1}$ and $p_{1}$, and Network 2 chooses $s_{2}$ and $p_{2}$ simultaneously.

Proposition 5: In both Game 3.1 and Game 3.2, the equilibrium prices are as follows: in the non-separable case:

$$
q=0, \quad s_{i}=p_{i}=a / 2,
$$

with $i=1,2$ and, in the separable case:

$$
q=0, \quad s_{i}=p_{i}=t^{m},
$$

with $i=1,2$, where $x\left(t^{m}\right)+t^{m} x^{\prime}\left(t^{m}\right) \equiv 0$.

Proposition 5 shows that under symmetric reciprocity on the termination fees, Network 1 sets the interconnection fee equal to its marginal cost (zero) and both networks set the other two prices at the monopoly level. This happens independently of whether Firm 1 sets the interconnection fee in advance or simultaneously with all the other prices. Thus, imposing symmetric reciprocity eliminates the 'double marginalisation' effect: the firms charge their monopoly prices on both internal and outgoing calls. In comparison to Game 1, the welfare of all consumers, as well as both firms' profits is higher. Note also that symmetric reciprocity implies exact parity, that is, at equilibrium, $s_{i}=p_{i}+q_{i}$.

The intuition behind the results is as follows. The symmetric reciprocity constraint enables Network 1 to control the total price $p_{1}+q$ of its outgoing calls. Thus, Network 1 is able to fully reap the benefits of price decreases of components of $A_{1} B_{2}$, thereby eliminating the double marginalisation effect. Network 1's pricing of components $A_{1}$ and $B_{1}$ become equivalent to pricing of components $A_{1}$ and $B_{2}$. Thus, Network 1 acts as a monopolist who 
perfectly controls the price of both its internal and its outgoing calls. Looking at the separable case for simplicity, Network 1's problem for outgoing calls is:

$$
\max _{q}\left(p^{o}(q)+q\right) x\left(p^{o}(q)+q\right)
$$

where $p^{o}(q)=\operatorname{argmax}_{p} p x(p+q)$. The optimal price for outgoing calls is then the monopoly price $t^{m}$, which can be written as $t^{m}=p^{o}\left(q^{*}\right)+q^{*}$. This monopoly price can only be achieved (in both the simultaneous and sequential structures) by setting $q=q^{*}=0$, since $p^{o}(0)=t^{m}$ and $p^{o}(q)$ are strictly increasing. In other words, first, symmetric reciprocity allows Network 1 to achieve the monopoly pricing for outgoing calls; second, monopoly pricing can only occur when the first mark-up is zero. Thus, Network 1 sets the termination fee at marginal cost, that is, zero.

\section{The subscription decision}

Turning to the consumers' subscription decision, each consumer earns the same surplus independent of her network affiliation, since internal calls cost as much as outgoing calls. In the non-separable case:

$$
V^{(3)}\left(n_{i}, n_{j}\right)=\frac{a^{2}\left(n_{i}+n_{j}\right)}{8\left(b+c\left(n_{i}+n_{j}\right)\right)}
$$

and in the separable case:

$$
V^{(3)}\left(n_{i}, n_{j}\right)=\left(n_{i}+n_{j}\right) v\left(t^{m}\right) .
$$

Proposition 6: In the non-separable quadratic case, in addition to $\{0,0\}$, the equilibria are:

- $\{\{1 / 2,1 / 2\}\}$, for $0<\lambda \leq \frac{a^{2}}{4(b+c)}$;

- $\left\{n_{*}^{(3)}(\lambda), n_{*}^{(3)}(\lambda)\right\}$, 


$$
\text { for } \frac{a^{2}}{4(b+c)}<\lambda \leq \frac{a^{2}}{4 b}
$$

where

$$
n_{*}^{(3)}(\lambda) \equiv \frac{a^{2}-4 \lambda b}{8 \lambda c} .
$$

In the separable case, in addition to $\{0,0\}$, there is only one additional equilibrium, $\{1 / 2,1 / 2\}$, for $0<\lambda \leq 2 v\left(s^{m}\right)$. For proof see Appendix.

Thus, symmetric reciprocity eliminates the corner (monopoly) equilibria which may arise both in Game 1 and Game 2; the symmetric one is the only full-coverage equilibrium. In the price sub-game, symmetric reciprocity eliminates the power of the leader to set different prices for termination, and the leader finds it to its benefit to set termination charges to marginal cost, resulting in equal prices for outgoing and internal calls. This eliminates the possibility of a price squeeze which would generate the monopoly (corner) equilibria. Thus, symmetric reciprocity—a conduct rule-has a structural effect, the elimination of corner equilibria and the promotion of duopoly over monopoly.

\section{WELFARE ANALYSIS}

Table 5.2 summarises the welfare analysis for the quadratic case of Game 1 and Game 3, which are both symmetric. Let CS denote the total consumer surplus, and $\Pi$ denote the sum of the profits of the two networks.

The rankings in the table hold for any value of $\lambda$ such that the equilibria exist. The profits' ranking is a consequence of the 'double marginalisation' effect, which is present only in the symmetric equilibrium of Game 1. At the corner equilibria, only one firm is producing; hence there is no demand for outgoing calls; and in Game 3, the symmetric reciprocity constraint eliminates the double marginalisation problem by incorporating the termination fee in Firm 1's decision problem.

The elimination of double marginalisation also increases total consumer surplus, since it lowers the equilibrium prices to their monopoly level. This happens both at the corner equilibria of Game 1 and at the equilibrium of Game 3. The latter, however, is preferable from the consumers' perspective, since their total 'transportation costs' are minimised at the symmetric outcome. 
Table 5.2 Welfare analysis

\begin{tabular}{cccc}
\hline & $\begin{array}{c}\text { Game 1 } \\
\text { (symmetric) }\end{array}$ & $\begin{array}{c}\text { Game 2 } \\
\text { (corner) }\end{array}$ & $\begin{array}{c}\text { Game 3 } \\
\text { (symmetric reciprocity) }\end{array}$ \\
\hline CS $\frac{a^{2}(13 b+9 c)}{72(b+c)(2 b+c)}-\frac{\lambda}{4}<$ & $\frac{a^{2}}{8(b+c)}-\frac{\lambda}{2}<$ & $\frac{a^{2}}{8(b+c)}-\frac{\lambda}{4}$ \\
$\Pi \quad \frac{a^{2}(17 b+9 c)}{36(b+c)(2 b+c)}<$ & $\frac{a^{2}}{4(b+c)}=$ & $\frac{a^{2}}{4(b+c)}$ \\
\hline
\end{tabular}

\section{EXTENSIONS}

\section{Heterogeneous Preferences}

In this section, it is shown that the results obtained for the short run in the previous sections hold even if the consumers have heterogeneous preferences for telephone services, provided that these preferences are not correlated with their preferences over network variety. In other words, the critical condition is that each consumer's position on the unit segment is independent of her preferences for telephone services.

In the model of Section 2, each consumer has the same preferences over telephone consumption. One way in which this assumption can be generalised is to assume that the consumer located at $\theta \in[0,1]$ has utility function:

$$
U^{\psi}(x, m)=\psi(\theta)\left[\int_{0}^{1}\left(a x_{\tau}-\frac{b}{2} x_{\tau}^{2}\right) d \tau-\frac{c}{2} \int_{0}^{1} \int_{0}^{1} x_{\tau} x_{\tau^{\prime}} d \tau d \tau^{\prime}\right]+m
$$

where $\psi$ is any integrable function defined on [0,1]. $\psi(\theta)$ measures the intensity of preference for telecommunications services for a consumer of type $\theta$. The corresponding demand functions are:

and

$$
x_{i i}^{\psi}=\frac{\psi(\theta)}{\gamma}\left(a-s_{i}+\frac{c}{b} n_{j}\left(p_{i}+q_{j}-s_{i}\right)\right)
$$




$$
x_{i j}^{\psi}=\frac{\psi(\theta)}{\gamma}\left(a-p_{i}-q_{j}+\frac{c}{b} n_{i}\left(s_{i}-p_{i}-q_{j}\right)\right) .
$$

and the profit function is:

$$
\begin{aligned}
\Pi_{i}^{\psi} & =m_{i} n_{i} s_{i} \frac{1}{\gamma}\left(a-s_{i}+\frac{c}{b} n_{j}\left(p_{i}+q_{j}-s_{i}\right)\right) \\
& +m_{i} n_{j} p_{i} \frac{1}{\gamma}\left(a-p_{i}-q_{j}+\frac{c}{b} n_{i}\left(s_{i}-p_{i}-q_{j}\right)\right), \\
& +m_{i} n_{i} q_{i} \frac{1}{\gamma}\left(a-p_{j}-q_{i}+\frac{c}{b} n_{j}\left(s_{j}-p_{j}-q_{i}\right)\right)
\end{aligned}
$$

where $m_{i} \equiv \int_{N_{i}} \psi(\theta) d \theta \equiv n_{i} E\left[\psi(\theta) \mid \theta \in N_{i}\right] \equiv n_{i} \psi_{i}$.

With these preferences, the short run equilibrium outcome in Game 1 remains unchanged. In Game 3, it is still the case that $s_{i}^{(3)}=a / 2$ and $p_{i}^{(3)}=1 / 2(a-q)$, as in the case of identical preferences. Network 1 now chooses:

$$
q^{(3)}=\frac{a b\left(\psi_{2}-\psi_{1}\right)}{2 \psi_{2}\left(b+c n_{2}\right)-\psi_{1}\left(b+c n_{1}\right)}
$$

Thus $q^{(3)}=0$ if and only if $\psi_{2}=\psi_{1}$, which holds if the consumers' intensity of preference for telephone calls (represented by the function $\psi$ ) are not correlated with their preferences for variety (represented by their position $\theta$ on the unit segment).

\section{Different Costs}

In the main part of the chapter it is assumed that the costs of the two networks were the same, and without further loss of generality assumed them to be zero. This assumption is reasonable if the two networks operate in the same area and face the same geographic conditions, and the technology of production is well known and exhibits constant returns to scale. However, symmetric reciprocity has also been proposed and practiced in international telephony, where the costs can easily differ across the two networks (countries), as well as in mobile networks where there are increasing returns to scale and, even with the same technology, firms can have quite different 
termination costs if their scales of operation differ significantly. This section investigates the effects of symmetric reciprocity when marginal production costs differ across networks. It is shown that the regulatory imposition of a generalised symmetric reciprocity rule has the same effects as in the equal costs case. The generalised symmetric reciprocity rule takes the form of equal mark-ups above marginal costs, and called 'symmetric reciprocity in markups'. Notice that, in the presence of different unit costs (as in the example above), imposing a rule that would set equal termination prices across networks would result in foreclosure of one or more higher cost networks, which is exactly what the regulation aims to avoid. Symmetric reciprocity in mark-ups should be imposed instead.

For simplicity, only cases with linear demands and independent goods are shown; the proof for general demand is identical. Assume that Network $i$ 's marginal cost of providing either origination or termination services is $m_{i}$, $i=1,2$. Then Firm $i$ 's profit $\Pi_{i}$ satisfies:

$$
\begin{aligned}
b \Pi_{i} & =\left(s_{i}-2 m_{i}\right) n_{i}^{2}\left(a-s_{i}\right)+\left(p_{i}-m_{i}\right) n_{i} n_{j}\left(a-p_{i}-q_{j}\right) \\
& +\left(q_{i}-m_{i}\right) n_{i} n_{j}\left(a-p_{j}-q_{i}\right) .
\end{aligned}
$$

First, as a benchmark, note that the prices that maximise the joint profits $\Pi_{1}+\Pi_{2}$ are:

$$
s_{i}=\frac{a}{2}+m_{i}
$$

and

$$
p_{i}+q_{j}=1 / 2\left(a+m_{1}+m_{2}\right)
$$

Solving for the Nash equilibrium of the strategic symmetry price sub-game (Game 1), yields:

$$
\begin{gathered}
s_{i}=\frac{a}{2}+m_{i}, \\
p_{i}=q_{j}=1 / 3\left(a+m_{j}+2 m_{i}\right)
\end{gathered}
$$

and

$$
p_{i}+q_{j}=1 / 3\left(2 a+m_{1}+m_{2}\right) .
$$


Thus, in Game 1, at the Nash equilibrium, $p_{i}+q_{j}$ is higher than the joint profit-maximising level. As before, this is due to the double marginalisation effect, that is, to the failure of each network to internalise the full effect of changing its prices.

The generalised symmetric reciprocity rule is applied to mark-ups; that is, it is imposed that the mark-up above cost of Network 1 is equal to the markup above cost of Network 2:

$$
q_{2}-m_{2}=q_{1}-m_{1}
$$

Maximising $\Pi_{1}$, subject to this constraint, with respect to $s_{1}, p_{1}$ and $q_{1}$, maximising $\Pi_{2}$ with respect to $s_{2}$ and $p_{2}$, and solving for the equilibrium yields:

$$
\begin{gathered}
s_{i}=\frac{a}{2}+m_{i}, \\
p_{j}=1 / 2\left(a-m_{i}+m_{j}\right),
\end{gathered}
$$

and $q_{i}=m_{i}$, for $i=1,2$. Therefore, the imposition of symmetric reciprocity on mark-ups results in pricing of termination at cost. It follows that outgoing calls are priced at:

$$
p_{i}+q_{j}=1 / 2\left(a+m_{1}+m_{2}\right)
$$

and consequently, all prices are at their collusive levels. This is because imposing 'symmetric reciprocity in mark-ups' on the termination fees eliminates the double marginalisation. ${ }^{20}$

\section{Low Switching Costs}

Up to this point, it has been assumed that the two networks set their prices only after the consumers make irreversible subscription decisions. This feature of the model aims to capture the idea that changing network affiliation is costly in a particular way: it is only feasible in the 'long run'. The basic model is close to reality, as telecommunications providers have observed that consumers tend to be slow in revising their subscription decisions. However, to test robustness of the results to alternative specifications this subsection allows for simultaneous subscription and quantity decisions by the consumers, which follow the announcement of prices. 
The analysis with low switching costs is complicated by the presence of network externalities. After firms have chosen prices, consumers will choose different quantities of output, and possibly different network affiliation as well, depending on what each consumer believes the other consumers will do. Thus, the demand function faced by a network, as well as its size, depends on coordination among the consumers in the sub-game. This makes each firm's maximisation problem dependent on its conjectures about the consumers' choices in the sub-game starting after the firms set their prices. Moreover, when setting prices, it is natural to expect that a network will take actions to tilt the coordination of the consumers in its favour. Thus, the problem with low switching costs is considerably more complex than the one of high switching costs. The next Proposition, however, establishes the existence of corner equilibria when consumers have a weak preference for variety.

Proposition 7: Consider the following multi-stage games:

Game 1': in Stage 1, the networks set their three respective prices simultaneously; in Stage 2 the consumers make their subscription and consumption decisions.

Game 2': in Stage 1, Network 1 chooses $q_{i}$; in Stage 2, the two networks set all other prices simultaneously; in Stage 3 , the consumers make their subscription and consumption decisions.

Game 3.1': in Stage 1, Network 1 chooses $q_{1}=q_{2}$; in Stage 2, Network 2 sets $s_{2}$, and $p_{2}$, and, simultaneously, Network 1 sets $s_{1}$ and $p_{1}$; in Stage 3, the consumers make their subscription and consumption decisions.

Game 3.2': in Stage 1, Network 2 sets $s_{2}$, and $p_{2}$, and, simultaneously, Network 1 sets $s_{1}, p_{1}, q_{1}$ and $q_{2}$, subject to $q_{1}=q_{2}$; in Stage 2 , the consumers make their subscription and consumption decisions.

In all four games above, with quadratic preferences, corner equilibria exist, where $n_{i}=1-n_{j}=0, s_{i}=a / 2, p_{i}=0$ and $q_{i}>a$, for all $\lambda \leq \frac{a^{2}}{8(b+c)}$.

Proof: in each of these games, given prices $s_{i}=a / 2, p_{i}=0$ and $q_{i}>a$, suppose that all consumers, except the one located at point $\theta$, subscribe to network $i$.Then this consumer realises utility:

$$
\frac{\left(a-s_{i}\right)^{2}}{2 b+c)}-\lambda \theta=\frac{a^{2}}{8(b+c)}-\lambda \theta
$$

if she subscribes to network $i$. Since $q_{i}>a$, she would make no outgoing calls and therefore realise non-positive utility if she subscribed to Network 
$j$. Therefore, for $\frac{a^{2}}{8(b+c)} \geq \lambda$, the consumer at $\theta$ joins Network $i$ for every $\theta \in[0,1]$. Under this condition, Network $j$ makes zero profit for any $\left(s_{2}, p_{2}, q_{2}\right)$, and Network $i$ maximises its profit by setting $s_{i}=a / 2$. This establishes $n_{i}=1, n_{j}=0$ as an equilibrium.

The intuition of the proof is as follows. When the quantity and subscription choices are simultaneous, a 'large' network can set a high termination fee to reduce the number of phone calls that reach it (originating from the other network). Then a customer of the other network is essentially restricted to calls within her (small) network and will realise low utility. Thus, such actions of a large network will result in more consumers leaving the smaller network and joining the larger one. The small network is unable to effectively counter the high termination fee of the larger network, until, at equilibrium, the 'small' network has no subscribers. Therefore, in this case, corner equilibria always exist. ${ }^{21}$

Proposition 7 indicates that, when switching costs are low, symmetric reciprocity does not eliminate the corner equilibria if preference for variety is weak. This is in contrast with the results of Proposition 6. Therefore, imposing symmetric reciprocity may not be as effective if the consumers have low switching costs.

\section{CONCLUDING REMARKS}

This study analysed equilibrium interconnection fees set by competing twoway networks. The analysis finds that commitment in interconnection fees by a dominant network results in a price squeeze and possible foreclosure of the rival network. When the costs of the networks are equal, if the rule of symmetric reciprocity is imposed (that is, the networks are forced to charge each other equal amounts for call termination), the strategic advantage of the first-mover is eliminated, and prices of end-to-end services are lower. Furthermore, under symmetric reciprocity, each network sets its termination fee equal to zero (that is, marginal cost) and parity holds, so that each network charges itself as much as it charges others for the same service. Thus, the imposition of a regulatory rule of symmetric reciprocity induces the networks to choose a low (common) termination fee in equilibrium.

Symmetric reciprocity internalises the vertical externality, eliminates the double marginalisation, and results in lower prices even in comparison to the simultaneous action pricing game. Under symmetric reciprocity, both consumers' surplus and industry profits are higher than in the simultaneous pricing game. These results demonstrate the benefits of requiring symmetric 
reciprocity in setting interconnection charges, and hence justify imposition of this rule when implementing the Telecommunications Act of 1996.

The subscription decision stage typically has multiple equilibria, including corner ones, where all consumers subscribe to only one network. However, when symmetric reciprocity is imposed, the network with the strategic advantage chooses to set termination fees at cost. As a result, there are no corner equilibria. This is an added benefit of symmetric reciprocity, since a corner equilibrium would result in a significant 'transportation cost' welfare loss. When the costs of the networks differ, the appropriate regulatory rule is symmetric reciprocity of termination price mark-ups above cost.

The main part of the analysis is done in game structures which try to capture the notion that consumers are slower in revising their subscription decisions than they are in adjusting their quantity in response to price changes. This assumption is currently seen by telecommunications providers as realistic.

In the extensions section, the possibility of allowing subscribers to simultaneously choose network affiliation and consumption levels, after the networks have set their prices is considered. As pointed out there, in such a setup, there are consumers' coordination problems that make it difficult to even write the maximisation problem of the firms without specific assumptions regarding the way they coordinate. In this setup, Proposition 7 establishes the existence of corner equilibria when consumers have weak preference for network variety. This may suggest that, if consumers revise their subscription choices as easily as their consumption decisions, symmetric reciprocity as a regulatory rule may not be sufficient to eliminate monopolisation and foreclosure effects. However, the analysis considers that symmetric reciprocity is an effective regulatory rule on the assumption (supported by practitioners' statements) that consumers tend to adjust their quantity decisions much more frequently than their subscription decisions. 


\section{APPENDIX}

\section{Proof of Proposition 1}

In the separable case, the first order conditions are:

$$
\begin{aligned}
x\left(s_{i}\right)+s_{i} x^{\prime}\left(s_{i}\right) & =0, \\
x\left(p_{i}+q_{j}\right)+p_{i} x^{\prime}\left(p_{i}+q_{j}\right) & =0, \\
x\left(p_{j}+q_{i}\right)+q_{i} x^{\prime}\left(p_{j}+q_{i}\right) & =0
\end{aligned}
$$

The first equation implies $s_{1}=s_{2}=s^{m}$. Subtracting the third from the second equation yields:

$$
\left(p_{i}-q_{i}\right) x^{\prime}\left(p_{i}+q_{j}\right)=0
$$

which implies $p_{i}=q_{i}=t^{o} / 2$, where $t$ is defined as $x\left(t^{o}\right)+\frac{t^{o}}{2} x^{\prime}\left(t^{o}\right) \equiv 0$.

With non-separable preferences, maximising $\mathrm{II}_{i}$ with respect to $s_{i}, p_{i}$, and $q_{i}$, given $s_{j}, p_{j}$, and $q_{j}$ yields the equilibrium prices.

\section{Proof of Proposition 2}

The five numbers indicated in the proposition are:

$$
\begin{array}{ll}
\lambda_{1}^{(1)} \equiv \frac{5 a^{2} b}{18(c+2 b)^{2}}, & \lambda_{2}^{(1)} \equiv \frac{5 a^{2}}{72(b+c)}, \\
\lambda_{3}^{(1)} \equiv \frac{a^{2}}{8(b+c)}, & \lambda_{4}^{(1)} \equiv \frac{a^{2}(9 c+13 b)}{36(b+c)(2 b+c)}, \\
\text { and } & \lambda_{5}^{(1)} \equiv \frac{13 a^{2}}{72 b} .
\end{array}
$$

With $c=0$, the preferences are separable, and:

$$
\lambda_{1}^{(1)}=\lambda_{2}^{(1)}=\frac{5 a^{2}}{72 b}=v\left(s^{m}\right)-v\left(t^{o}\right),
$$




$$
\lambda_{3}^{(1)}=\frac{a^{2}}{8 b}=v\left(s^{m}\right)
$$

and

$$
\lambda_{4}^{(1)}=\lambda_{5}^{(1)}=\frac{13 a^{2}}{72 b}=v\left(s^{m}\right)+v\left(t^{o}\right) .
$$

First, $\{0,0\}$ is always an equilibrium: each consumer has no incentive to subscribe to any network if no other consumer subscribes.

Second, the corners $\{0,1\}$ and $\{1,0\}$ are equilibrium outcomes if and only if:

$$
V^{(1)}(1,0)-\lambda \geq \max \left\{0, V^{(1)}(0,1)\right\}
$$

In the non-separable case, this is equivalent (for $n_{i}=1-n_{j}=1$ ) to:

$$
\frac{a^{2}}{8(b+c)}-\lambda \geq \max \left\{0, \frac{\left(a-p_{j}-q_{i}\right)^{2}}{2 b+\phi)}\right\}
$$

Since the equilibrium prices $p_{j}$ and $q_{i}$ are arbitrary, corner equilibria exist for any $\lambda \leq \lambda_{3}^{(1)}$. In the separable case, the inequality above becomes:

$$
v\left(s^{m}\right)-\lambda \geq \max \left\{0, v\left(p_{j}+q_{i}\right)\right\},
$$

which is satisfied for arbitrary prices $p_{j}$ and $q_{i}$ if and only if $\lambda \leq v\left(s^{m}\right)$.

Any other pair $\left\{n_{1}, n_{2}\right\}$, such that $n_{1}+n_{2} \leq 1$, is an equilibrium if and only if:

$$
V\left(n_{i}, n_{j}\right)-\lambda n_{i}=\max \left\{0, V\left(n_{j}, n_{i}\right)-\lambda\left(1-n_{i}\right)\right\},
$$

with $i=1,2$. In words, the marginal consumer subscribing to Network 1 (resp. 2), located at point $n_{1}$ (resp. $1-n_{2}$ ), must earn the same payoff as his next best alternative. This condition is necessary because, if it does not hold, the consumers located in some neighbourhood of $n_{1}$, or $1-n_{2}$, have an 
incentive to revise their subscription decision. The condition is also sufficient because it implies:

$$
V\left(n_{i}, n_{j}\right)-\lambda d>\max \left\{0, V\left(n_{j}, n_{i}\right)-\lambda(1-d)\right\},
$$

for all $d \in\left[0, n_{i}\right)$; thus no infra marginal consumer of any network has any incentive to revise her subscription decision.

In principle, Condition (5.1) can be satisfied in four cases, considering all possible combinations of equalities and inequalities. However, $V\left(n_{i}, n_{j}\right)-\lambda n_{i}=0$ implies:

$$
\begin{aligned}
V\left(n_{j}, n_{i}\right)-\lambda n_{j} & =\max \left\{0, V\left(n_{i}, n_{j}\right)-\lambda\left(1-n_{j}\right)\right\} \\
& =\max \left\{0, \lambda n_{i}-\lambda\left(1-n_{j}\right)\right\} \\
& =\max \left\{0, \lambda\left(n_{i}+n_{j}-1\right)\right\} \\
& =0 .
\end{aligned}
$$

Thus only two cases are possible: that is, either:

$$
V\left(n_{i}, n_{j}\right)-\lambda n_{i}=V\left(n_{j}, n_{i}\right)-\lambda\left(1-n_{i}\right) \geq 0
$$

or

$$
V\left(n_{i}, n_{j}\right)-\lambda n_{i}=0>V\left(n_{j}, n_{i}\right)-\lambda\left(1-n_{i}\right)
$$

with $i=1,2$.

First, suppose that (5.2) holds. Then, summing the two equalities and simplifying yields $n_{1}+n_{2}=1$, that is, the two networks cover the whole market. Thus the equalities in (5.2) are equivalent to the single equation in $\tau$ :

$$
V(\tau, 1-\tau)-V(1-\tau, \tau)=\lambda(2 \tau-1)
$$

In the non-separable case, this equation has solutions $\tau_{1}=1 / 2, \tau_{2}=1 / 2-\delta(\lambda)$, and $\tau_{3}=1 / 2+\delta(\lambda)$. The pair $\{1 / 2,1 / 2\}$ is an equilibrium if and only if:

$$
V(1 / 2,1 / 2)-1 / 2 \lambda \geq 0
$$


or, equivalently, $\lambda \leq \lambda_{3}$.

Since $\delta$ is increasing in $\lambda, \delta\left(\lambda_{1}^{(1)}\right)=0$ and $\delta\left(\lambda_{2}^{(1)}\right)=1 / 2$, the pairs $\{1 / 2+\delta(\lambda), 1-\delta(\lambda)\}$ and $\{1 / 2-\delta(\lambda), 1+\delta(\lambda)\}$ can be equilibrium outcomes only if $\lambda_{1}^{(1)} \leq \lambda \leq \lambda_{2}^{(1)}$. This last condition is also sufficient, since it implies that the inequalities in (5.2) are satisfied.

In the separable case, equation (5.4) becomes linear in $\tau$. For $\lambda \neq v\left(s^{m}\right)-v\left(t^{o}\right)$, the only solution is $\tau_{1}=1 / 2$. Thus $\{1 / 2,1 / 2\}$ is an equilibrium if and only if:

$$
V(1 / 2,1 / 2)-\lambda 1 / 2 \geq 0
$$

that is, $0<\lambda \leq v\left(s^{m}\right)+v\left(t^{o}\right)$.

For $\lambda=v\left(s^{m}\right)-v\left(t^{0}\right),\{n, 1-n\}$ is an equilibrium for any $n \in[0,1]$, since $V(n, 1-n)-\left(v\left(s^{m}\right)-v\left(t^{o}\right)\right) n=v\left(t^{o}\right)>0$.

Now suppose that (5.3) holds. Then, all solutions different from $\{0,0\}$ must have both $n_{1}$ and $n_{2}$ strictly positive, because, in the non-separable case, $n_{i}=0$ and $V\left(n_{i}, n_{j}\right)-\lambda n_{i}=0$ imply:

$$
\frac{a^{2}\left(4 b n_{j}\right)}{72 b\left(b+c n_{j}\right)}=0,
$$

that is, $n_{j}=0$; and in the separable case, $n_{i}=0$ and $n_{i} v\left(s^{m}\right)+n_{j} v\left(t^{o}\right)-\lambda n_{i}=0$ imply $n_{j}=0$.

In the separable case, subtracting one equality in (5.3) from the other yields:

$$
\left(n_{i}-n_{j}\right)\left(v\left(s^{m}\right)-v\left(t^{o}\right)\right)=\lambda\left(n_{i}-n_{j}\right)
$$

which implies $n_{i}=n_{j}$ unless $\lambda=v\left(s^{m}\right)-v\left(t^{o}\right)$. For $\lambda \neq v\left(s^{m}\right)-v\left(t^{o}\right)$, $n\left(v\left(s^{m}\right)+v\left(t^{o}\right)-\lambda\right)=0$ implies $n=0$; hence no other equilibrium exists. For $\lambda=v\left(s^{m}\right)-v\left(t^{o}\right)$, the equality $n\left(v\left(s^{m}\right)+v\left(t^{o}\right)-\lambda\right)=0$ holds for any $n$; hence $\{n, n\}$ is an equilibrium for any $n \in[0,1 / 2]$.

In the non-separable case, rewriting the equalities in (5.3) as: 


$$
a^{2}\left(4 b n_{j}+9 b n_{i}+9 c n_{i} n_{j}+9 c n_{i}^{2}\right)=\lambda n_{i} 72\left(b+c n_{i}+c n_{j}\right)\left(b+c n_{i}\right),
$$

dividing through by $n_{i}$, subtracting one from the other and rearranging yields:

$$
-\frac{4 a^{2} b}{n_{1} n_{2}}\left(n_{1}+n_{2}\right)\left(n_{1}-n_{2}\right)=7 \lambda c\left(b z c\left(n_{1}+n_{2}\right)\right)\left(n_{1}-n_{2}\right),
$$

which implies $n_{1}=n_{2}$ : in fact, if $n_{1}-n_{2} \neq 0$, then dividing by $\left(n_{1}-n_{2}\right)$ yields:

$$
-\frac{4 a^{2} b}{n_{1} n_{2}}\left(n_{1}+n_{2}\right)=7 \quad \lambda c\left(b z c\left(n_{1}+n_{2}\right)\right),
$$

a contradiction.

Thus, the two equalities in (5.3) are equivalent to $0=V(n, n)-\lambda n$, or:

$$
\frac{1}{n} V(n, n)=\lambda
$$

If $n \in[0,1 / 2]$ satisfies (5.5) then $\{n, n\}$ is an equilibrium, since it also satisfies the inequalities in (5.3):

$$
V(n, n)-\lambda(1-n)=\lambda n-\lambda(1-n) \leq 0,
$$

Since $\frac{1}{n} V(n, n)$ is decreasing in $n$ and $2 V(1 / 2,1 / 2)=\lambda_{3}$, there is no equilibrium where (5.3) holds if $0<\lambda<\lambda_{3}^{(1)}$. For any $\lambda$ such that $\lambda_{3}^{(1)} \leq \lambda<\lambda_{4}^{(1)}$, there is a unique $n$ that satisfies (5.5), given by $n_{*}^{(1)}(\lambda)$.

\section{Proof of Proposition 4}

Substituting the equilibrium prices into the consumers utility functions yields:

$$
V_{(2)}^{1}\left(n_{1}, n_{2}\right)=\frac{a^{2}}{72 b}\left(4 n_{2}+9 n_{1}\right)
$$


and

$$
V_{(2)}^{2}\left(n_{2}, n_{1}\right)=\frac{a^{2}}{32 b}\left(n_{1}+4 n_{2}\right),
$$

Proceeding as in the proof of Proposition 2, $\{1,0\}$ is an equilibrium for $\lambda \leq \frac{5 a^{2}}{72 b}$ and $\{0,1\}$ is an equilibrium for $\lambda \leq \frac{3 a^{2}}{32 b}$.

For all other pairs $\left\{n_{1}, n_{2}\right\}$, attention is restricted to the two cases:

$$
V_{(2)}^{i}\left(n_{i}, n_{j}\right)-\lambda n_{i}=V_{(2)}^{i}\left(n_{j}, n_{i}\right)-\lambda\left(1-n_{i}\right)>0
$$

and

$$
V_{(2)}^{i}\left(n_{i}, n_{j}\right)-\lambda n_{i}=0>V_{(2)}^{i}\left(n_{j}, n_{i}\right)-\lambda\left(1-n_{i}\right),
$$

with $i=1,2$.

As in Game 1, the first case implies full coverage, $n_{1}+n_{2}=1$; and the equality for the marginal consumer is:

$$
\frac{a^{2}}{18 b}+\frac{5 a^{2}}{72 b} n-\lambda n=\frac{a^{2}}{32 b}+\frac{3 a^{2}}{32 b}(1-n)-\lambda(1-n)
$$

with solution $n=n^{(2)}(\lambda)$. The pair $\left\{n^{(2)}(\lambda), 1-n^{(2)}(\lambda)\right\}$ is an equilibrium for $\lambda \leq \frac{5 a^{2}}{72 b}$, since this implies:

$$
V_{(2)}^{i}\left(n^{(2)}(\lambda), 1-n^{(2)}(\lambda)\right)-\lambda n^{(2)}(\lambda) \geq 0 .
$$

In the other case, the system:

$$
V_{(2)}^{1}\left(n_{1}, n_{2}\right)=\frac{a^{2}}{72 b}\left(4 n_{2}+9 n_{1}\right)-\lambda n_{1}=0,
$$




$$
V_{(2)}^{2}\left(n_{2}, n_{1}\right)=\frac{a^{2}}{32 b}\left(n_{1}+4 n_{2}\right)-\lambda n_{2}=0,
$$

yields $n_{1}=n_{2}=0$.

\section{Proof of Proposition 6}

Corner equilibria do not exist since $V^{(3)}(1)=\frac{a^{2}}{8(b+c)}>0$ and, for any $\lambda>0$,

$$
V^{(3)}(1)-\lambda<\max \left\{0, V^{(3)}(1)\right\}
$$

Any other point $\left\{n_{1}, n_{2}\right\}$, with $n_{1}+n_{2} \leq 1$, is an equilibrium if and only if:

$$
V_{i}^{(3)}\left(n_{i}, n_{j}\right)-\lambda n_{i}=\max \left\{0, V_{j}^{(3)}\left(n_{j}, n_{i}\right)-\lambda\left(1-n_{i}\right)\right\},
$$

with $i=1,2$. As in the proof of proposition of Game 1 , only two cases are possible. Case 1 implies full coverage; hence $\{n, 1-n\}$ is an equilibrium only if:

$$
\frac{a^{2}}{8(b+c)}-\lambda n=\frac{a^{2}}{8(b+c)}-\lambda(1-n),
$$

which implies $n=1 / 2$. If $\lambda \leq \frac{a^{2}}{4(b+c)}$, then $V_{i}^{(3)}(1 / 2,1 / 2)-\lambda 1 / 2 \geq 0$. Thus $\{1 / 2,1 / 2\}$ is an equilibrium if and only if $\lambda \leq \frac{a^{2}}{4(b+c)}$.

$$
\begin{gathered}
\text { In Case 2, } V_{i}^{(3)}\left(n_{i}, n_{j}\right)-\lambda n_{i}=\frac{a^{2}\left(n_{i}+n_{j}\right)}{8\left(b+c\left(n_{i}+n_{j}\right)\right)}-\lambda n_{i}=0 \text { implies: } \\
a^{2}\left(n_{i}+n_{j}\right)-\lambda n_{i} 8\left(b+c\left(n_{i}+n_{j}\right)\right)=0
\end{gathered}
$$

with $i=1,2$. Subtracting one equality from the other yields:

$$
8 \lambda\left(b+c\left(n_{1}+n_{2}\right)\right)\left(n_{1}-n_{2}\right)=0,
$$


which implies $n_{1}=n_{2}$; otherwise, dividing by $\left(n_{1}-n_{2}\right)$ generates a contradiction. Thus the two equalities are equivalent to:

$$
V_{i}^{(3)}(n, n)-\lambda n=\frac{a^{2} n}{4(b+2 c n)}-\lambda n=0,
$$

which implies $n=0$ or $n=n_{*}^{(3)}(\lambda)$. Since $n=n_{*}^{(3)}(\lambda)$ is decreasing in $\lambda$, $n_{*}^{(3)}\left(\frac{a^{2}}{4(b+c)}\right)=1 / 2$ and $n_{*}^{(3)}\left(\frac{a^{2}}{4 b}\right)=0,\left\{n_{*}^{(3)}(\lambda), n_{*}^{(3)}(\lambda)\right\}$ is an equilibrium for $\lambda \in\left[\frac{a^{2}}{4(b+c)}, \frac{a^{2}}{4 b}\right]$.

In the separable case, Case 1 implies:

$$
v\left(t^{m}\right)-\lambda n=v\left(t^{m}\right)-\lambda(1-n)
$$

that is, $n=1 / 2$. Thus $\{1 / 2,1 / 2\}$ is an equilibrium for all $\lambda$ such that $v\left(t^{m}\right)-1 / 2 \lambda \geq 0$, that is, $\lambda \leq 2 v\left(t^{m}\right)$.

In Case 2, $\left(n_{i}+n_{j}\right) v\left(t^{m}\right)-\lambda n_{i}=0$, for $i=1,2$, implies $n_{i}=n_{2}=0$. 


\section{ACKNOWLEDGEMENTS}

The authors thank Anette Boom, Jose Campa, Michael Davis, Roy Radner, Basil Sharpe, Chris Stefanadis, Larry White, Sang-Sueng Yi and participants of the Workshop on Interconnection and Interoperability, Wellington, New Zealand, the Consortium for Research on Telecommunications Policy at Northwestern University, the Telecommunications Policy Research Conference and the Industrial Organisation Seminar at the Stern School of Business for useful discussions and comments. Financial support from BellSouth New Zealand and the Markley Foundation is gratefully acknowledged.

\section{NOTES}

1. See the historical evidence of AT\&T foreclosures in Gabel and Weiman (1994).

2. For a general discussion of network effects and compatibility see Economides (1996).

3. Of course, besides mandatory interconnection, non-prohibitive interconnection (access) fees are necessary so that no company in the network is foreclosed. Non-prohibitive interconnection fees is also a goal of the state and federal regulation of telecommunications. The literature on access fees in one-sided bottlenecks is large. One point of view derives such access fees from monopoly end-to-end services, resulting in the 'efficient component pricing rule' (ECPR) proposed by Baumol and Sidak (1994a, b) and Willig (1979). For a critical view of the usefulness of the ECPR in bottleneck cases and for a proposal of cost-based access fees for one-sided bottlenecks, see Economides and White (1995).

4. Telecom New Zealand imposed a significant fee for all calls that terminated in its network, but refused to pay any fee for calls terminated in competitors' networks. As a consequence, upstart Bell South New Zealand exited the local telecommunications market, and Clear remained in the market but has continually refused to pay a significant portion of interconnection fees to Telecom New Zealand claiming that if it paid the full interconnection fees it would be driven out of business.

5. See Telecommunications Act of 1996, section 251(b) 'Each local exchange carrier has the following duties: ... (5) The duty to establish reciprocal compensation arrangements for the transport and termination of telecommunications'.

6. See, for example, Radner (2003).

7. Laffont et al. (1998) analyse a game with the traditional sequence of moves in the Hotelling framework. They limit the analysis to the case in which the interconnection fees are set exogenously and equal to each other, at a relatively low level. Hence, their analysis cannot capture the strategic implications of a network's ability to control the termination fee that a rival network would have to pay —one of the main goals in this paper. These range from purely fibre optic technology such as Fibre-to-the-Premise/Home (FTTP/FTTH) to a mix of fibre optic and traditional wireline solutions such as Hybrid Fibre Coaxial (HFC), the same technology used by cable Internet service providers.

8. Double marginalisation resulting in higher prices for two vertically disintegrated firms than for a merged one was first observed by Cournot (1927). For a discussion of this issue in a network setting see Economides and Salop (1992).

9. It is not crucial whether the two component prices for calls across networks are paid directly by the consumer or the consumer pays the originating network for end-to-end service and the originating network buys termination services from the other network. 
10. Differentiation in preferences of consumers across networks may arise when the networks have brand names that different consumers value differently, or if the networks use different technical specifications for which (business) customer's equipment is more or less compatible. Tardiff (1995) reports evidence of brand loyalty toward long distance carriers.

11. We use the subscript $s$ for the separable case.

12. This last assumption on the third derivative guarantees that each network's marginal revenue is decreasing.

13. The quadratic specification can be interpreted as a second-order approximation of any general utility function with substitute products.

14. As is standard in the telecommunication literature, it is assumed that consumers derive no utility from receiving calls.

15. We assume that investment costs are zero. Investment costs that depend on network size, $F_{i}\left(n_{i}\right)$, would play a similar role as the parameter $\lambda$.

16. The aggregate demand functions are: $D_{i i}=n_{i}^{2} x_{i i}$, and $D_{i j}=n_{i} n_{j} x_{i j}$, where $i, j=1,2, i \neq j$.

17. To see that $s^{m}<t^{o}$, let $m(z)=x(z)+z x^{\prime}(z)$ and $M(z)=x(z)+z x^{\prime}(z) / 2$. The result follows immediately from the fact that $M(z)$ and $m(z)$ are monotone and $M(z)-m(z)=-z x^{\prime}(z) / 2>0$.

18. This effect was noted by Cournot (1927) in a simpler model with only two complementary components. For an application to network industries see Economides (1989). The problem is similar to the 'double marginalisation' problem that arises when a single good is produced by a manufacturer and sold by a retailer (Spengler 1950).

19. $V^{(1)}$ is well defined for $n_{i} \in(0,1]$. For $n_{i}=0, V^{(1)}$ depends $p_{i}+q_{j}$, which are not uniquely determined.

20. However, parity fails, $p_{i}+q_{i} \neq s_{i}$, unless marginal costs are equal across networks.

21. This is in contrast to the results of Laffont et al. (1998) who finds that no corner equilibria exist in the case of low switching costs. The difference arises from the fact that they assume that the termination fee is low and it is exogenously given.

\section{REFERENCES}

Armstrong, M. (1998), 'Network Interconnection in Telecommunications’, Economic Journal, 108, 545-64.

Baumol, W.J. and Sidak, J.G. (1994a), 'The Pricing of Inputs Sold to Competitors', Yale Journal of Regulation, 11, 171-202.

Baumol, W.J. and Sidak, J.G. (1994b), Toward Competition in Local Telephony, Washington DC: The MIT Press and the American Enterprise Institute.

Chou, C. and Shy, O. (1990), 'Network Effects without Network Externalities', International Journal of Industrial Organization, 8, 259-70.

Church, J. and Gandal, N. (1993), 'Systems Competition, Vertical Merger and Foreclosure', mimeo, University of Calgary.

Cournot, A. (1927), Researches into the Mathematical Principles of the Theory of Wealth, (N.T. Bacon Trans.), New York: Macmillan. 
Doganoglu, T. and Yair, T. (1996), 'Network Competition with Reciprocal and Proportional Access Charge Rules', SUNY at Stony Brook Discussion Paper DP96-01.

Economides, N. (1989), 'Desirability of Compatibility in the Absence of Network Externalities', American Economic Review, 79, 1165-81.

Economides, N. (1993), 'Mixed Bundling in Duopoly', Discussion Paper EC-93-29, Stern School of Business, New York University.

Economides, N. (1996), 'The Economics of Networks', International Journal of Industrial Organization, 14, 673-99.

Economides, N. and Salop, S.C. (1992), 'Competition and Integration among Complements, and Network Market Structure', Journal of Industrial Economics, 40, 105-23.

Economides, N. and White, L.J. (1994), 'Networks and Compatibility: Implications for Antitrust', European Economic Review, 38, 651-62.

Economides, N. and White, L.J. (1995), 'Access and Interconnection Pricing: How Efficient is the Efficient Components Pricing Rule?’, Antitrust Bulletin, XL, 55779.

Economides, N. and Woroch, G. (1992), 'Benefits and Pitfalls of Network Interconnection,' Discussion Paper EC-92-31, Stern School of Business, New York University.

Gabel, D. and Weiman, D.F. (1994), 'Historical Perspectives on Interconnection between Competing Local Operating Companies: The United States, 1894-1914', mimeo, Queens College, City University of New York.

Jeon, S., Wang, G.H. and Yoon, C.H. (1999), 'A Model of Interconnection between Land and Mobile Networks', mimeo, Sogang University, Korea.

Laffont, J., Rey, P. and Tirole, J. (1998), 'Network Competition: II. Price Discrimination', Rand Journal of Economics, 29, 38-56.

Matutes, C. and Regibeau, P. (1988), 'Mix and Match: Product Compatibility without Network Externalities', Rand Journal of Economics, 19, 219-34.

Radner, R. (2003), 'Viscous Demand', Journal of Economic Theory, 112, 189-231.

Selten, R. (1975), 'Re-examination of the Perfectness Concept for Equilibrium Points in Extensive Games', International Journal of Game Theory, 4, 25-55.

Spengler, J. (1950), 'Vertical Integration and Antitrust Policy', Journal of Political Economy, 58, 347-52.

Willig, R.D. (1979), ‘The Theory of Network Access Pricing', in H.M. Trebing (ed.), Issues in Public Regulation, Michigan State University Public Utilities Papers, Proceedings of the Institute of Public Utilities. 